\title{
Language Learning Strategies and Vocabulary Size of Iranian EFL Learners
}

\author{
Ali Akbar Ansarin \\ English Department, Faculty of Persian Literature \& Foreign Languages, University of Tabriz, Tabriz, Iran \\ Email: aa-ansarin@tabrizu.ac.ir \\ Mohammad Zohrabi \\ English Department, Faculty of Persian Literature \& Foreign Languages, University of Tabriz, Tabriz, Iran \\ Email: Mohammad Zohrabi@gmail.com \\ Simin Zeynali \\ MA University Student of ELT, Tabriz, Iran \\ Email:simin_zeynali2000@yahoo.com
}

\begin{abstract}
The present study aimed to determine the relationship between language learning strategies and vocabulary size in Iranian EFL learners. Therefore, 150 Zoha English Language Learners were given Oxford university and Cambridge university placement test. Oxford strategies inventory for language learning (SILL) were used, as well. According to Brown (2000) taxonomy, three classification of strategies as metacognitive, cognitive, social/affective strategies were included in the present study. Besides, Vocabulary Size Test based on the Norbert Schmitt's test, to measure the vocabulary size by assessing the learners' basic knowledge of common meaning of words in order to the relationship between language learning strategies and vocabulary size would be distinguished. After the data have been elicited, the results were statistically analyzed by using SPSS software. The statistical study of the three proficiency levels manifest that the mean and standard deviation of metacognitive strategy is the most frequently used among others. It is also, understood that the employment of F-Test demonstrates that advanced proficiency level learners use the language learning strategies more than others. Furthermore, it is proved that advanced level learners have higher vocabulary size in relation to other proficiency levels. The findings of present study will be advantageous to English language teachers to develop effective vocabulary teaching and to provide learners with variety of successful language learning strategies.
\end{abstract}

Index Terms - language learning strategy, vocabulary size

\section{BACKGROUND}

Learning a second or foreign language requires the manipulation of four main skills, namely, listening, reading, speaking, and writing which lead to effective communication. It is obvious that vocabulary is an indispensible part of any communication, so without a vocabulary, no meaningful communication can take place and meaningful communication relies heavily on vocabulary. One fundamental factor is the amount of vocabulary an individual possesses. Therefore, vocabulary forms the meaningful part of any language (McCarthy, 1988; as cited in Hamzah, Kafipour, \& Kumar Abdullah, 2009).

Vocabulary is the group of words that a person or a group of people knows how to use. Your vocabulary is all the words you know and use regularly. Vocabulary is a group or stock of words used in a particular way by a certain group of people regarding their language. It is important and it is vital to communicate with others and understand what one is reading. It is obvious that information, which is known as a language-based activity, is fundamentally and profoundly dependent on vocabulary knowledge. Learners must have access to the meanings of words that teachers, their surrogates, other adults, books or films use to guide them into contemplating known concepts in novel ways in order to learn something new.

Second language (L2) acquisition depends crucially on the development of a strong vocabulary. In second language acquisition (SLA), a sub-discipline known as second language vocabulary acquisition (SLVA), researchers have focused their attention on the need for second language learners to optimize their vocabulary knowledge (Singleton, 1999; Schmitt, 2000). Over the years, estimates of student vocabulary size have varied greatly, hindered in part by issues such as the types of vocabularies being considered (e.g., receptive/ productive or oral/print).

It is evident that vocabulary is indispensable for successful communication in any language. The question is addressed which specific part of the target lexicon should be presented to language learners at what stage and it is followed by a short summary of how word knowledge has been defined in the SLA literature. Consequently, the focus of attention changed from acquisition to vocabulary assessment. The familiarity of learners with learning strategies has 
been emphasized as a facilitating factor in the process of language learning. Besides, as regards second or foreign language learning, many researchers have been done in order to deal with language learning strategies (LLS).These researches had a feasible goal, was the identification of the ways of enhancing the language learner to become more self-directed, resourceful, effective, and flexible in their learning. Consequently, the invaluable importance of learning strategies has been emphasized as a rudimentary factor in order to overcome the difficulties of L2 learning (O'Malley \& Chamott, 1990; Weinstein et al, 2000; Hall, 2000).

Moreover, the acquisition of vocabulary has been emphasized in the second language pedagogy and research. Consequently, the neglected concept of vocabulary has been shifted to the position of some significance. As well as the familiarity of language learning skills, the development of vocabulary knowledge has been emphasized as a fundamental factor in order to deal with all learning processes. Learners are encountered with various vocabularies in different texts, so the fear of unknown vocabulary has threatened learners as big hindrance in the process of L2 learning. The appropriate meaning of a word in a given context can be regarded as a dimension of vocabulary knowledge, so its increase raises the vocabulary size of the learner.

Based on the ideas discussed above, it is crucial to be aware of how learners adopt the strategies effectively with vocabulary size. Thus, the principal focus of present study is to examine which language learning strategies are effective for the learners' use and how the usefulness of vocabulary size is linked in order to help teachers to design lesson plan and to construct feasible instructions so that effectively support learners' competence in English language.

\section{METHOD}

\section{Participants}

The present study was conducted at Zoha English Language Center. A total of 150 EFL learners, 47 males and 143 females, within the age range of 15 - 32 participated in the study. All participants were from Interchange Intro level up to TOEFL level. These learners were considered as consistent learners of the center. They were involved in an English language program at Zoha Center during the Fall 2011 semester.

TABLE 1

CHARACTERISTICS OF THE PARTICIPANTS

\begin{tabular}{|ll|}
\hline Number of the participants & 150 \\
Age range & $15-32$ \\
General English proficiency level & Elementary, Intermediate, Advanced \\
Sex & Females\& Males \\
\hline
\end{tabular}

\section{Instrument}

An already determined standard placement test of Oxford university and Cambridge university (2001, version 1) was used to divide the participants into elementary, intermediate, and advance proficiency levels. This instrument included 60 multiple-choice question, cloze comprehension passage, vocabulary, and grammar sections.

Another instrument, which was applied in the present study, was the Strategy Inventory Learning (SILL, Version 7).Besides, some background information questions about the learners' age, gender, name, and proficiency levels were included. The SILL was used to ascertain the frequency of students' uses of language learning strategies.

Regarding the content validity of the inventory, Oxford and Burry- Stock (1995) state that the content validity of the instrument was determined by professional judgment and it is found to be very high.

Although the version SILL 7 includes 50 questions and 6 subscales, in the present study due to some infeasibilities 'only 35 questions and 3 subscales as metacognitive (items 15-23), cognitive(items 1-14), and social/ affective strategies(items 24-35) were included.

The following numbers indicates how often the learner uses the strategies.

Never or almost never true of me $=1$

Generally not true of $\mathrm{me}=2$

Somewhat true of me $=3$

Generally true of me $=4$

Always or almost always true of me $=5$

The participants were required to write their answers on a separate answer sheet. Having all the answers completed, the values assigned to each item in each section were added. Then, they were divided into the number of items in each part. The same procedures were repeated for each section and values ranging between 1 to 5 were obtained. These values demonstrate the profile of a learner. That is, the strategies used by learners and their frequency. Due to the high accessibility of SILL which was achieved in previous studies such as Bobko (2001), and Litwin's (1995) Cronbach alpha was .82, so the reliability of the test is acceptable. Thus, the test is a reliable instrument to estimate students' English Language strategies. Another study was done by other researchers who, proved the accessibility of the SILL test by using internal consistency reliability of the SILL as .94 based on a 505-person sample (Yang, 2010) and .92 based on a 315-person sample (Watanabe, 1990). Content validity is 99 based on independent raters (Oxford \&BurryStock, 1995). 
The second tool, which was used in the present study was Schmitt's vocabulary learning strategy questionnaire adopted from Bennet (2006) with a reliability coefficient of 0.78. Another study was done by Ozdamar (2002), who used Cronbach Alpha. According to his findings, the reliability of each item was high (Alpha=0.8851).

The SILL has been translated into several languages such as Persian, Japanese, Spanish, Turkish, and Chinese. Therefore, in the present study, the translated version of SILL was used for elementary level learners. In the present study, the vocabulary level test was used to find out the size of vocabulary items. The test was designed by Norbert Schmitt (2008, version 2). Schmitt (2001) wrote three new forms of the test following the original specification by taking fresh samples of words for each level. Its utility has been proved for diagnostic vocabulary teaching and has been widely used and validated by different researchers (Laufer \&Nation, 1995; Laufer and Nation 1999; Laufer, 1998; Lufer and Paribakht, 1998). Meara (1996) calles it the nearest thing we have to standard test in vocabulary. Vocabulary size testing has been found to be a useful tool in diagnostic or placement exams. It can discriminate between groups of learners (Meara, 1996) and aid in admissions (Laufer, 2003), as well as help in placing students into appropriate institutional placement levels within a program (Laufer \& Nation, 1999). The format of the test involves word definition matching exercise. Although, this test is regarded as a standard practice, it is the words that test takers need to match to the definitions provided. That is, definitions rather than words comprise the test items. This unconventional format was designed in order to involve as little reading as possible while at the same time minimizing chances of guessing correctly (Read, 2001).

Each frequency level of the test consisted of six words and three definitions. Testees were required to match target words with their corresponding definitions as demonstrated below:

1 business

2 clock

3 horse

4 pencil

5 shoe

6 wall

As indicated above, there were 3 words to be selected by the students. Test-takers need, however, to know 6 words because they should check every word against the definitions in order to make correct matches.

\section{FINDINGS}

Three types of learning strategies as cognitive, metacognitive, and social/affective strategies were included based on Brown's (2000) taxonomies of learning strategies. In order to focus on three categories of SILL, the researcher adopted descriptive statistics to explore the mean, standard deviation, range, minimum, and maximum of scores of each item of SILL. Therefore, table 2 presents the descriptive statistics of results.

TABLE 2

SUMMARY OF DESCRIPTIVE STATISTICS BETWEEN LANGUAGE LEARNING STRATEGIES AND VOCABULARY SIZE

\begin{tabular}{|c|c|c|c|c|c|c|}
\hline & & cognitive & metacognitive & Social/Affective & LLS & Vocabulary size \\
\hline \multirow[t]{2}{*}{$\mathrm{N}$} & Valid & 149 & 148 & 149 & 148 & 149 \\
\hline & Missing & 0 & 1 & 0 & 1 & 0 \\
\hline \multicolumn{2}{|c|}{ Mean } & 28.5839 & 46.3176 & 21.2483 & 96.2027 & 21.7584 \\
\hline \multicolumn{2}{|c|}{ Skewness } & .182 & -.346 & -.650 & -.251 & -.747 \\
\hline \multicolumn{2}{|c|}{ Std. error of skewness } & .199 & .199 & .199 & .199 & .199 \\
\hline \multicolumn{2}{|c|}{ Range } & 29.00 & 47.00 & 26.00 & 83.00 & 26.00 \\
\hline \multicolumn{2}{|c|}{ Maximum } & 43.00 & 67.00 & 30.00 & 132.00 & 30.00 \\
\hline
\end{tabular}

Table 2 demonstrates the most and least frequently used strategies in EFL learners. The results are expressed as mean $\pm \mathrm{SD}(\mathrm{n}=149)$. According to the descriptive findings of the survey, the first variable is the cognitive strategy of the learners (28.58 \pm 5.38$)$. Besides, its range, minimum, and maximum scores are respectively 29,14 , and 43 . Furthermore, the second variable is metacognitive strategy of the subjects $(46.31 \pm 9.17)$. Besides, its range, minimum, maximum scores are respectively 47, 20, and 67.

In addition, Table 2 shows social/ affective strategy of the learners with a mean of 21.24, and standard deviation of 5.42. Besides, its range, minimum, maximum scores are respectively 26, 4, and 30. Table 2 indicates that the mean score of language learning strategy among learners is 96.20, and its standard deviation is 16.72. Besides, its range, minimum, maximum scores are respectively 83, 49, and 132. Table 2 manifests that the mean of vocabulary size among learners is 21.75 , and its standard deviation is 6.39 . Besides, its range, minimum, maximum scores are respectively 26 , 4, and 30. The results elicited from the survey illustrate the most and least frequently used strategies respectively as metacognitive and social/ affective strategies. 
TABLE 3

THE PEARSON CORRELATION BETWEEN LANGUAGE LEARNING STRATEGIES AND VOCABULARY SIZE

\begin{tabular}{llll}
\hline & & LLS & \multicolumn{1}{c}{ Vocabulary } \\
\hline LLS & Pearson Correlation & 1 & $.461(* *)$ \\
& Sig. (2-tailed) &. & .000 \\
\multirow{4}{*}{ Vocab Size } & $\mathrm{N}$ & 148 & 148 \\
& Pearson Correlation & $.461(* *)$ & 1 \\
& Sig. (2-tailed) & .000 &. \\
& $\mathrm{~N}$ & 148 & 149 \\
\hline
\end{tabular}

The relationship between scores of language learning strategies and vocabulary size of learners, was determined by the Pearson correlation coefficient. The information of table 3 demonstrates that, $\mathrm{p}<0.05$ is significant level, so between two variables there are direct and significant relationship. Data in table 4.17 shows that $\mathrm{R}^{2-}=0.21$, so based on the regression plot $\% 21$ of the changes observed in the subject vocabulary size could be predicted by LLS in different proficiency levels.

TABLE 4

THE PEARSON CORRELATION BETWEEN LANGUAGE LEARNING STRATEGIES AND VOCABULARY SIZE IN ELEMENTARY LEVEL

\begin{tabular}{llll}
\hline & & LLS & Vocabulary size \\
\hline LLS & Pearson Correlation & 1 & $.238(*)$ \\
& Sig. (2-tailed) &. & .031 \\
& $\mathrm{~N}$ & 83 & 83 \\
Vocabulary size & Pearson Correlation & $.238^{*}$ & 1 \\
& Sig. (2-tailed) & .031 &. \\
& $\mathrm{~N}$ & 83 & 83 \\
\hline \multicolumn{2}{c}{$*$ Correlation is significant at the 0.05 level (2-tailed). }
\end{tabular}

The relationship between scores of language learning strategies and vocabulary size of learners, in elementary levels was determined by the Pearson correlation coefficient. Table 4 demonstrates that since $\mathrm{p}<0.05$, so there is statistically significant relationship between two variables. Table 4.18 shows that since $\mathrm{R}^{2-}=0.06$, therefore, based on the regression plot $6 \%$ of the changes observed in the subject vocabulary size could be predicted by LLS in elementary levels.

TABLE 5

THE PEARSON CORRELATION BETWEEN LANGUAGE LEARNING STRATEGIES AND VOCABULARY SIZE INTERMEDIATE LEVEL

\begin{tabular}{llll}
\hline & & LLS & Vocabulary size \\
\hline LLS & Pearson Correlation & 1 & .093 \\
& Sig. (2-tailed) &. & .613 \\
Vocab Size & N & 32 & 32 \\
& Pearson Correlation & .093 & 1 \\
& Sig. (2-tailed) & .613 &. \\
& $\mathrm{~N}$ & 32 & 33 \\
\hline
\end{tabular}

The relationship between scores of language learning strategies and vocabulary size of learners, in intermediate levels was determined by the Pearson correlation coefficient. Table 5 demonstrates that there is not statistically significant relationship between two variables $(\mathrm{p}>0.05)$. Data in table 5 shows that since $\mathrm{p}=0.61$, there is not direct and significant relationship between language learning strategies and vocabulary size of intermediate learners.

TABLE 6

THE PEARSON CORRELATION BETWEEN LANGUAGE LEARNING STRATEGIES AND VOCABULARY SIZE

\begin{tabular}{llll}
\hline & & LLS & Vocabulary size \\
\hline LLS & Pearson Correlation & 1 & .147 \\
& Sig. (2-tailed) &. & .414 \\
\multirow{4}{*}{ Vocabulary size } & N & 33 & 33 \\
& Pearson Correlation & .147 & 1 \\
& Sig. (2-tailed) & .414 &. \\
& $\mathrm{~N}$ & 33 & 33 \\
\hline
\end{tabular}

The relationship between scores of language learning strategies and vocabulary size of learners in intermediate levels was determined by the Pearson correlation coefficient . The information of table 6 demonstrates that, $p>0.05$ is significant level, so between two variables there aren't direct and significant relationship. Data in Table 6 shows that since $\mathrm{p}=0.41$, there is not direct and significant relationship between language learning strategies and vocabulary size of advanced learners. 


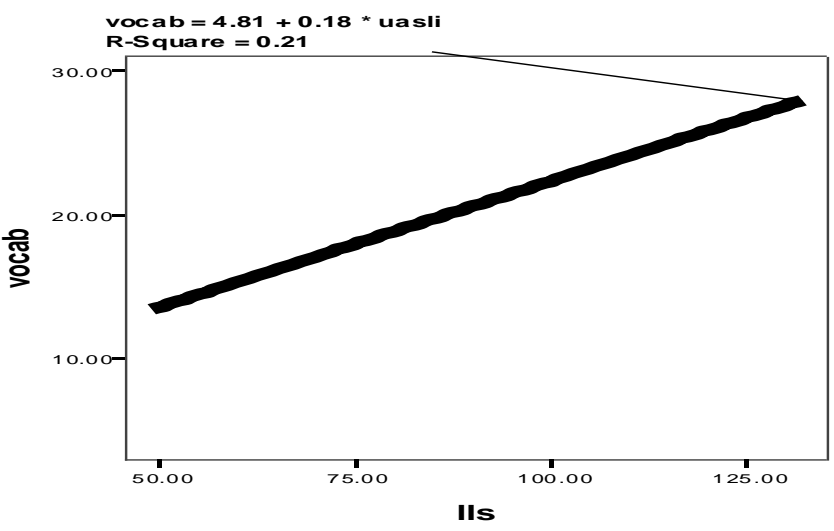

Linear Regression

Figure 1 Correlations between language learning strategies and vocabulary size

\section{DiSCUSSIONS}

\section{Metacognitive Strategies}

It is obvious from the results that this group of strategies is more frequently used among the other categories of strategies. Learners use 'pay attention when someone is speaking English' (item number 32) at 62.7\%, then they use 'I think about the progress in learning English'(item 38) at 61.2\%, they apply 'try to find out to be a better learner of English' (item number 33) at 60.5\%, they use 'notice my English mistakes and use that information to help me do better '(item number 31) at $59.2 \%$, they apply 'try to find as many ways as I can use my English' (item number 30)at 54\%, they use 'have clear goals for improving my English skills '(item number 37) at 53.6\%, they use 'look for opportunities to read as much as possible in English' (item number 36) at 53.4\%, they 'look for people I can talk in English '(item number 35 ) at $53.2 \%$, they use 'plan my schedule so I will have enough time to study English' (item number 34 ) at $51.9 \%$. These findings manifest that learners have used a higher level of Metalinguistic awareness. Meta linguistics knowledge is considered as a term to express executive function, strategies which require planning for learning, thinking about the learning process as it is taking place, monitoring of one's production or comprehension and evaluating learning after an activity is completed (O'Malley 1985).

The results of relationships between metacognitive strategies and vocabulary size illustrate that the advanced learners use higher vocabulary size, in contrast their pairs with other levels, the elementary level use the least vocabulary size. Therefore, those advanced learners who have higher proficiency of the target language applied metacognitive strategy more than others. The majorities of successful learners who usually have definite goals for learning and stronger capabilities of self-monitoring, self-management, and self-evaluation than unsuccessful learners have better ability to plan their learning carefully, monitor their learning processes ,and evaluate their accomplishments frequently.

\section{Cognitive Strategy}

The results manifest that the learners, 'first skim an English passage (read over the passage quickly) then go back and read carefully' (item number 18) at 56.1\%, they 'start conversations in English' (item number 14) at $52.1 \%$, they use 'make summaries of information that I hear or read in English' ( item number 23) at 51.3\%, they apply 'try to talk like native English speakers' ( item number 11) at 51.2\% , they 'start conversations in English' ( item number 14) at 52.1\%, they use 'say or write new English words several times' ( item number 10) at 49.8\%, they apply 'practice the sounds of English' (item number 12) at $49.8 \%$, they 'use the English words I know in different ways' (item number 13) at $49.2 \%$, they use 'write notes, messages, letters, or reports in English' (item number 17) at 49\%, they 'try not to translate word for word' (item number 22) at 48.1\%, they use 'watch English language TV shows spoken in English or go to movies spoken in English' (item number 15) at 47.5\%, they use 'read for pleasure in English ' (item number 16) at 40.2\% . The results manifest an idea about the learners' choice of strategies which are surface strategies that did not require an immense effort and did not help an effective learning. By considering the differences in using various kinds of cognitive strategies between advanced learners and elementary learners on vocabulary size, significant differences can be understood.

That is, advanced learners who like to use deep processing information such as gathering more vocabularies by improving English learning through summarizing, speaking, reading, and writing English which require more time and effort, so can be regarded as time consuming and longitude task. However, their pairs who are intermediate and elementary level learners with lower vocabulary size, process the task superficially not deeply (Schmitt, 1993). Consequently, these kinds of learners tend to use surface strategies more frequently than deep strategies. Therefore, it could be understood that the advanced learners with higher vocabulary size applied cognitive strategies more frequently than the intermediate and elementary learners with lower vocabulary size.

Social /Affective Strategies 
The results of the study illustrate that the frequency of the social/affective strategies among learners is different. They use the strategy 'If do not understand something in English, I ask the other person to slow down and say it again' (item number 45) at 59.1\%, they "ask English speakers to correct me when I talk' (item number 46) at 55.2\%, they 'try to learn about the culture of English speakers' (item number) at 53.8\%, they 'ask question in English'(item number 49) at $52.7 \%$, they "encourage myself to speak English even when I am afraid of making a mistake ' (item number 40 ) at $51.3 \%$, they 'ask for help from English speakers ' (item number 48 ) at $48.5 \%$, they 'talk to someone else about how I feel when I am learning English '(item number 44) at $45.6 \%$, they 'give myself a reward or treat when I do well in English' (item number 41 ) at $42.6 \%$, they 'write down my feelings in a language learning dairy'(item number 43 ) at $35.4 \%$. Therefore, the results of study demonstrate that the learners who use the affective/social strategies might be more aware of this strategy taxonomies and its importance, know better how to efficiently regulate their emotions and have tendency to deliberately look for opportunities in order to interact and negotiate as co-constructed or mutual actions with target language users communicatively so that improve their proficiency of the language (Stern, 1983). Therefore, advanced learners who have higher vocabulary size, like to employ social/affective strategies more than intermediate and elementary learners.

The present study tends to illustrate the application of language learning strategies and their relation with the vocabulary size. The results disclose that the learners use various kinds of strategies. They apply metacognitive strategies more often than all the other types of strategies in order to monitor and evaluate their process of learning. They also utilize cognitive strategies, which have a direct influence on the processing of information. They use the social affective strategies in order to interact and negotiate bilaterally with other English speakers.

The advanced learners with higher vocabulary size use particular strategies more than the intermediate and elementary learners with lower vocabulary size. They monitor their process of learning, utilize an image or picture to remember the word, and try to talk with English native speakers. Besides, the learners are instructed in order to use language-learning strategies appropriately in a given context.

The frequencies of the strategy use across various levels of language learners revealed that there are statistically significant variations among the proficiency levels and language learning strategy use. By comparing means of different levels as advanced learners with $(\mathrm{M}=112.48)$ intermediate learners with $(\mathrm{M}=94.59)$, and elementary learners with $(M=90.34)$, it is manifested that the advanced learners use language learning strategies more than other levels. Therefore, there is a positive relationship between the frequency of strategy use and the language proficiency. Nevertheless, not all L2 strategy-training studies have been successful or conclusive. Some training has been effective in various skill areas but not in others (Oxford, 1989). As Chamot and Kupper (1989) assert, high proficiency learners know how to use appropriate strategies to reach their learning goals, while low proficiency learners are less expert in their strategy use and choice. Oxford (1985) claims that successful language learners use a wide range of strategies that are most appropriate for their learning tasks.

Yang (1994) states that perceived proficiency levels have a significant effect on students' use of learning strategies. The better students perceive their language proficiency, the more often they use various learning strategies to assist them in learning English. The great significance of vocabulary knowledge has been considered by second language researchers (laufer \& Nation, 1999). Since the important role of vocabulary knowledge as a component of every language in communication, reading, speaking and other aspects of language learning, estimation of vocabulary size is considered as a great interest by many researchers. Over the years, the vocabulary size has been studied in order to clarify the concept of people's vocabulary size (Warning, 1997).

In the suggested research question of present study, it was intended to find out the relationship between vocabulary size and proficiency level of EFL learners. By using ANOVA or F_TEST, it is manifested that the P $<0.05$, so the relationship between vocabulary size and proficiency level is highly significant. Zareva (2005) also stated that the important factor in language learning is the relationship between vocabulary size and proficiency level. Therefore, the result can be supported by other researches that the more extensive one's vocabulary size, the higher their language proficiency will be (Nation, 2001). It was a little surprising that significant correlation was found between the vocabulary size and the language learning strategies in advanced, intermediate, and elementary levels.

The Pearson Correlation test was used in order to find out the relationship between vocabulary size and languagelearning strategies. The results of such study manifested that in elementary level learners $\left(\mathrm{P}<0.05\right.$ and $\left.\mathrm{R}^{2}=0.06\right)$, so there is significant relationship between vocabulary size and elementary level learners. However, in intermediate and advanced levels it was observed that $\mathrm{P}>0.05$, therefore, there weren't significant relationship between vocabulary size and language learning strategies of intermediate and advanced levels. At this part of the study, the researcher is supposed to reply the following hypothesis: There is no relationship between language learning strategies and the vocabulary size of Iranian EFL learners. Therefore, the researcher would like to apply null hypothesis or non-directional hypothesis in order to answer the proposed hypothesis. The null hypothesis states that there is no relationship between items under investigation. The statistical task is to reject the null hypothesis and to show that there is a relationship between language leaning strategies and vocabulary size.

In order to determine the relationship between the languages learning strategies and vocabulary size of the participants, a Pearson Correlation Test was used to analyze the data. One dependent variable (vocabulary size) was correlated with all the independent variables (metacognitive, cognitive, and social/affective strategies).The statistics 
revealed that there is a significant relationship between language learning strategies and vocabulary size ( $\mathrm{p}<.05$ ). Therefore, it can be understood that there is a positive relationship between languages learning strategies and vocabulary size. Therefore, the learners with higher vocabulary size use particular language learning strategies more than the learners with lower vocabulary size, so the more language learning strategies are used, the higher the vocabulary size become.

According to the results, the following pedagogical implications were provided. Unfortunately, some learners are not fully aware of the role of language learning strategies and vocabulary size in the process of second language learning. In addition, learning strategy is also a tool in empowering learners to make wise decision in terms of what to learn and how to learn. Moreover, some learners reported that they had not been informed about the existence of language learning strategies, so they were not able to use them. Consequently, teachers should help learners in order to cultivate and develop their awareness of language learning strategies. Besides, they should be informed about the appropriate use of learning strategies in the specific context and situation. Furthermore, the development of vocabulary size helps learners in order to deal with language skills more easily. Besides, it should be taken into consideration that vocabulary size is an indispensible tool in describing and explaining the development of foreign or second language learning. Furthermore, noticeable relationship in the utilization of language learning strategies and vocabulary size achieved by high proficiency learners should be taken into account.

With better understanding of concepts of language, learning strategies and vocabulary size, teachers and learners can better understand the situation of EFL learning. Moreover, by encouraging appropriate beliefs and providing effective instruction of language learning strategies according to learners' needs and situations, teachers can teach English more efficiently. In order to comprehend the learners' beliefs and attitudes about learning strategy and vocabulary size, some materials and methods can be used in the regular curriculum. For example, by using SILL and Schmitt's vocabulary level test in the classroom not only they could help teachers gather the information about learners' beliefs and their use of strategies, but also they could help learners in order to promote their awareness of their existing vocabulary size and learning strategies.

Learners are asked to deal with various tasks, so familiarity with language learning strategies can facilitate their process of learning and lead to better learning. Another implication of the present study is linked to the gap, which exists among different proficiency levels. That is, the fewer gaps among proficiency levels, the more language learning strategies and vocabulary size.

The present study found a significant relationship between language learning strategies and vocabulary size. Teachers should try to help learners to develop a positive belief and attitude towards learning strategies and vocabulary size as fundamental factors, which facilitate and flourish the English language learning. Besides, teachers should eradicate the negative beliefs and attitudes towards learning strategies and vocabulary size, which act as hindrance in the process of language learning.

Moreover, teachers should allow learners to become fully aware of their preferred learning strategies and specially help them become more responsible to meet their learning goals. That is, teachers are able to help learners become better language learners by training them in using the right strategies or appropriate strategies that suit their level. Training the learners with learning strategies, the objectives and goals could be achieved. Then, they will likely become more independent with exposure to the target language.

Due to the significant role of language learning strategies, it is expected that the attitudes of teachers and learners towards language learning and vocabulary size be up-dated. Furthermore, learners are asked to develop their scope of vocabulary size because of the significant relationship, which exists between vocabulary size and language learning strategies that lead to better learning of English language.

Finally, the goal of strategy training is for learners to be self-directed learners, so teachers must become knowledgeable about as many strategies as possible and introduce strategies which are not only related to the classroom situation but also considered authentic in real life strategies.

\section{REFERENCES}

[1] Bobko, P., Roth, P., \& Bobko, C. (2001). Correcting the effect size of d for range restriction and unreliability. Organizational Research Methods, 4 (1) 46-61.

[2] Brown, H. (2000). Principles of Language Learning and Teaching. 4th ed. NY: Longman.

[3] Chamot, A. U. \& Kupper, L. (1989). Learning strategies in foreign language Instruction. Foreign Language Annual, 22 , 13-24.

[4] Chamot, A. U. (2004). Issues in language learning strategy research and teaching. Electronic Journal of Foreign language Teaching, 1(1), 12-25.

[5] Hamzah, M. S. G., Kafipour, R., \& Abdullah, S. K. (2009). Vocabulary learning strategies of Iranian undergraduate EFL students and its relation to their vocabulary size. European Journal of Social Sciences, 11(1), 39-50.

[6] Laufer, B., \& Nation, P. (1995). Vocabulary size and use: lexical richness in L2 written production. Applied linguistic, 16(3), 307-322.

[7] Laufer, B. (2003). Vocabulary acquisition in a second language: Do learners really acquire most vocabulary by reading. Canadian modern language review, 59(4), 565-585.

[8] Mc Carthy. (1988). Vocabulary and language Teaching. New York: Longman. 
[9] Meara, P. (1980). Vocabulary Acquisition: A Neglected Aspect of Language Learning. Language Teaching and Linguistics: Abstracts. 15 (4): 221-246.

[10] Norbert, S. (2001). Developing and exploring the behavior of two new versions of the Vocabulary Levels Test. Cambridge University Press Language Testing 18-55.

[11] Nation, I. S. P. (2001). Learning Vocabulary in Another Language. Cambridge: Cambridge University Press.

[12] O’Malley, J.M. et al. (1985). Learning Strategy Applications with Students of English as a Second Language. TESOL Quarterly, 19(3), 557-584.

[13] O’Mally, J. M., \& Chamot, A. (1990). Learning strategies in second language acquisition (The Cambridge Applied Linguistics Series). Cambridge: Cambridge University Press.

[14] Oxford, R. (1989). Use of language learning strategies. A synthesis of studies with implications for strategy training, 17(2), 235-247.

[15] Oxford, R. L., \& Burry-Stock, J. A. (1995). Assessing the use of language learning strategies worldwide with the ESL/EFL version of the Strategy Inventory for Language Learning (SILL), 23, 1-23.

[16] Oxford, R. L. (2003). Relationships between second language learning strategies and proficiency in the context of learner autonomy and self-regulation. Revista Canaria deEstudios Ingleses (Canarian Journal of English Studies), 38, 109-126.

[17] Ozdamar, K. (2002). Paket programlarla istatistiksel veri analizi-1 (Statistical dataanalysis by custom softwares-1). Eskisehir: Kaan Kitabevi.

[18] Singleton, D. (1999). Exploring the Second Language Mental Lexicon. Cambridge: Cambridge University Press.

[19] Stern, H. (1983). Fundamental Concepts of Language Teaching. Oxford: Oxford University Press.

[20] Weinstein, D., Staffelbach, D., \& Biaggio, Maryka. (2000). Attention-deficit hyperactivity disorder and posttraumatic stress disorder: Differential diagnosis in childhood sexual abuse. Clinical Psychology Review, 20(3), 359-378.

[21] Yang, M. N. (2010). Language learning strategies of English as a foreign language university students in Korea. Asian EFL Journal, 9(2), 35-57.

[22] Yang, N. (1994). Study of factors affecting EFL learners' use of learning strategies: An investigation of Taiwanese college students. Paper presented at the Eleventh Conference on English Teaching and Learning in the Republic of China, Taipei, Taiwan.

Ali Akbar Ansarin is an associate professor of English at the Department of English in the University of Tabriz, Iran. He has been teaching at post graduate and graduate levels since 2000. His recent research interest areas are psycholinguistics, Second Language Acquisition, and Writing.

Mohammad Zohrabi is an assistant professor and has taught various courses both at undergraduate and graduate level at the University of Tabriz, Iran. He has published various articles in international journals and produced 4 books: A Dictionary of Research Terms in Applied Linguistics, A Dictionary of Language and Linguistics, Reading English in Action, and Active Reading Comprehension. His research interests include: program evaluation, material writing and evaluation, first and second language acquisition, teaching reading and writing skills, English for academic purposes, English for general purposes, and English for specific purposes.

Simin Zeynali, from Iran is an EFL instructor finalizing her MA course in TEFL in University of Tabriz, Aras International Campus, Tabriz, Iran holding a BA in the same field from Tabriz Islamic Azad University, Iran. She has been teaching General English in private language institutes in Tabriz from 2007 to date. She is interested in language teaching and learning, and is looking forward to conducting pioneering researches in psycholinguistics, applied linguistics, SLA, multiple intelligences, emotional intelligences, and discourse analyses. 